RESEARCH PAPER

\title{
Japanese spousal smoking study revisited: how a tobacco industry funded paper reached erroneous conclusions
}

\section{E Yano}

Objectives: To provide a participant's account of the development of a paper commissioned by the tobacco industry examining the reliability of self reported smoking status; to redress the distorted report of this Japanese spousal smoking study which evaluated the reliability and validity of self reported smoking status, and estimated confounding by diet and lifestyle factors.

Design: Repeated interviews on smoking status and its verification by environmental and biological markers for environmental tobacco smoke (ETS) exposure.

Setting: Urban wives in Osaka City and Sizuoka City, Japan

Participants: Semi-random sampling of 200 wives in each city. From the Osaka subjects, 100 nonsmoking wives were selected for the validity study.

Main outcome measures: Kappa coefficient for reliability of self reported smoking status. Correlation coefficients between environmental nicotine concentration, cotinine in saliva and urine, and self reported smoking status.

Results: The $\kappa$ coefficient for the repeated interview was high suggesting sufficient reliability of the response. The proportion of self reported current smokers misclassified as non-smokers was equivalent to the misclassified self reported non-smokers. Ambient concentration of nicotine and personal exposure to nicotine correlated with each other and also with salivary cotinine and self reported ETS exposure but not

Correspondence to: Professor Eiji Yano, Department of Hygiene and Public Health, Teikyo University School of Medicine, 2-11-1, Kaga, Itabashi-ku, Tokyo 1738605, Japan; eyano@ med.teikyo-u.ac.jp

Received

29 December 2003

Accepted 29 March 2005 with urinary cotinine/creatinine ratio (CCR). There was no major difference in diet and lifestyle related to husband's smoking status.

Conclusion: Self reported smoking status by Japanese wives shows high reliability. It also shows high validity when verified by both nicotine exposure and salivary cotinine, but not by CCR. A previous report questioning the credibility of self reported smoking status, based on questionable CCR, could thus be of dubious validity. In addition, possible dietary and lifestyle confounding factors associated with smoking husbands were not demonstrable, a finding not reported previously. Using all the data from this project changes the conclusion of the previous published report. In addition to the distortion of scientific findings by a tobacco industry affiliated researcher, anti-smoking campaigners made attempts to intimidate and suppress scientific activities. These distortions of science should be counteracted.
$\mathrm{T}$ here has been an extensive, controversial, and vociferous debate over the possibility of the causal association between exposure to environmental tobacco smoke (ETS) and lung cancer. The issue was precipitated by the publication of Hirayama's large cohort study from Japan. ${ }^{1} \mathrm{He}$ demonstrated a twofold increase in the risk of lung cancer among non-smoking wives with heavy smoking (20 or more cigarettes/day) husbands compared to those with nonsmoking spouses. However, this study has been the target of scientific and methodological criticism including that of Mantel $^{2}$ who criticised the inappropriate application of his method of summarising $\chi$ statistics. Part of the reason for these criticisms arose from the brevity of Hirayama's original publication, which did not include comprehensive information. When the detailed figures of the various confounding factors, reported in a Japanese journal by Hirayama, were used for the calculation to obtain $\chi$ statistics after stratification, his analysis was confirmed and the statistical criticisms were rebutted. ${ }^{3}$

However, following Hirayama's publication, another large cohort study performed by the American Cancer Society found no or very little association between ETS exposure and lung cancer. ${ }^{5}$ The author of that study queried cultural differences between study subjects, claiming that more Japanese than American women may conceal their smoking, meaning that some active smoking women may have been misclassified as passive smokers in the Hirayama study. Since women smokers tend to marry men who also smoke, it may be expected that there would be a higher incidence of lung cancer in wives of smoking husbands compared to those of non-smoking husbands. The possibility of confounding unhealthy dietary and lifestyle aspects more frequently occurring in families with smoking husbands was also raised as an additional explanation to explain the findings contrary to the Hirayama study.

\section{PART 1: CHRONOLOGY OF A TOBACCO INDUSTRY FUNDED STUDY}

In 1991 Dr Christopher Proctor, a British scientist then employed by the Covington and Burling law firm in Washington DC, invited me to become principal investigator on a study designed to evaluate the extent of this potential misclassification and confounding. Proctor is now British American Tobacco's head of science and regulation. The 2002 publication of Hong and Bero ${ }^{6}$ made the mistake of assuming that the study was originally initiated by me. I was aware from the beginning that the tobacco industry was funding the project. $^{7}$ Consequently, I repeatedly requested and was verbally assured by Proctor that despite the commercial

Abbreviations: CCR, cotinine: creatinine ratio; ETS, environmental tobacco smoke; IEMC, International ETS Management Committee 
source of the funding the observed scientific facts ascertained by the study would be respected absolutely.

The field work for the study took place in the autumn of 1991, with a second phase in June 1992. Proctor was provided with the data in March and August $1992^{8}$ in the expectation that he would be a co-author with me and my Japanese colleague Professor Jun Kagawa, the two principal investigators. I received a draft paper via fax from Proctor on 14 October 1992.' There was no list of authors on this draft. Shortly after I received the draft, Proctor and I spoke by phone where I questioned his interpretation of the data on misclassification and to illustrate my point I sent a fax to him on 27 October 1992. ${ }^{10}$

I received another draft from Proctor on 31 October 1992 which showed my name as sole author. ${ }^{11}$ In his cover letter, he accepted his overstatement ("Here is a revised version... with the conclusions somewhat watered down") and changed the focus from misclassification to confounding in the text. I received a third draft on 10 November 1992 in which text in the "misclassification" section of the Results was further deleted and the previous statement "The misclassification rates in this study are somewhat higher than those reported in similar studies of Western populations" had disappeared only to reappear in the final published version ${ }^{12}$ authored by Peter Lee (see below).

The publication of Hong and Bero's paper alerted me to the existence of a draft of the paper dated 21 April $1992^{13}$ bearing my and Kagawa's names. We did not write any of this draft. Subsequent searching located other drafts dated 28 May 1992 and 25 June 1992, where Peter Lee's name appeared as third author. ${ }^{14} 15$ The latter, forwarded to 10 tobacco industry officials, was described by Proctor as being a "close to final" version "restructured" by Proctor and Lee. Again, I never saw these drafts, despite my name being on them. As described, the first version of the paper I saw was on 14 October 1992.

A reference in Hong and Bero's paper describes how Lee, a researcher with an extensive history of paid consultancies with the tobacco industry, was included in the budget for the study to assist in the study design and in interpreting the data. According to the study plan, it was "not anticipated that $\mathrm{Mr}$ Lee will serve as a co-author of any of the publications flowing from the study". ${ }^{7}$ At no stage in my interactions with Proctor was Lee's name or role ever mentioned.

Correspondence from Proctor dated 14 and 21 April $1993^{16}{ }^{17}$ states he was working on a further draft of the paper. As described, I had major concerns about Proctor's treatment of the data I had submitted, as set out in his October 1992 draft. On 7 July 1993, apologising for the delay, I wrote to Proctor requesting that we speak by phone on this. ${ }^{18}$ My letter stated that the data I had collected challenged the urinary cotinine: creatinine ratio as the gold standard for tobacco exposure and that the questionnaire approach to determining smoking status was "reliable and valid" judging from the concordance of data we had collected from the repeated study and via nicotine monitors. I attached data demonstrating this. I stated that there were therefore "somewhat fundamental issues" we needed to talk about before the paper progressed further. Word about my concerns apparently spread, as notes from a meeting of the International ETS Management Committee (IEMC) at Geneva in June 1993 record: "The Japanese authors [Yano et al] felt uncomfortable about this [the results set out in the draft] and are reluctant to publish it." ${ }^{19}$

Again from the Hong and Bero paper, I learned that shortly after I had faxed Proctor about my ongoing concerns, he wrote to officials from six tobacco companies asking permission to remove me as author and have Lee submit the paper to a journal..$^{20}$ Some time later, I discovered that Lee as sole author had published a report on the study in the International Archives of Occupational and Environmental Health ${ }^{12}$ without my consent. (Hereafter, I refer to this as Lee's report to avoid confusion with the original study).

I first became aware that Lee was attempting to publish a report using the data I had collected when, in November 1994, I was approached at a Tokyo meeting by Dr Franz Adlkofer. Dr Adlkofer said he had been asked by the editorin-chief of the International Archives of Occupational and Environmental Health to review a manuscript which Lee had submitted to that journal based on these data. Adlkofer had previously published with G Lehnert, the journal's editor. ${ }^{21}$ Unbeknown to me at the time, Adlkofer was a senior scientist employed by the German tobacco industry's Verband der Cigarettenindustrie..$^{22}$ A 1983 industry document records Adlkofer as wanting the German industry to financially support Lehnert's work on cadmium because it was "necessary to maintain Prof. Lehnert's 'good will', with reference to public smoking". ${ }^{24}$

At a meeting at Adlkofer's Tokyo hotel also attended by Ernst Wynder, I explained to Adlkofer the details of the respective roles of Proctor and myself in the study, as described above, and the major concerns I had with the draft paper that I had seen. I explained that as a principal investigator on the study, I had decided not to pursue publication of the study because of the irreconcilable differences I was having with Proctor. He insisted that the study should be published by me and that I should reopen discussions about it with Proctor and Lee. ${ }^{25}$ After returning to my office I sent a fax to his hotel which illustrated my point about Lee's misclassification using the Lee's draft table to explain the scientific disagreement between Proctor and $\mathrm{I}^{26}$

In these circumstances, I assumed that Lee's report would not be published. It was only on reading the Hong and Bero paper relating to the background of the study, ${ }^{6}$ that I realised that Lee's report ${ }^{12}$ had in fact been published after being rejected by at least two other journals. ${ }^{27}$

On 11 April 1995, Lee wrote to the editor of the International Archives of Occupational and Environmental Health stating that he had revised the manuscript to make "it clearer that the study was planned by me with a Japanese scientist and market researcher brought in to help with the fieldwork" ${ }^{28}$ This statement, and that which appeared in the published paper, is a travesty of the truth about my role in the project, making me sound nothing more than a translator, technical assistant, and interviewer coach. It says nothing of my principal investigator status nor of the copious computations I supplied to Proctor.

The publication of Hong and Bero ${ }^{6}$ described the tobacco industry's intentions in commissioning the study. Most of the facts presented in their paper are in agreement with what I observed, the exception being that the person who proposed the project was Proctor and not me. Although the Hong and Bero report describes the role of the tobacco industry, it does not address the scientific meaning of the results of the study. Being the principal researcher of the study, it was with particular dismay that, on reviewing Lee's report, I discovered that Lee had both misconstrued the findings of the study and had failed to include in his report major significant results I had supplied to Proctor which did not support the tobacco industry's position. He even overturned my account of misclassification which Procter accepted. The result of this was that Lee's report reached conclusions that were totally at odds with the actual findings of the study. In order therefore to attempt to redress the situation, I consider I am obliged to now provide the actual findings of the study and a detailed interpretation of the results. 


\section{PART 2: THE “LEE REPORT” REVISITED}

\section{METHODS}

First phase study (November 1991)

Subjects

A semi-random sampling method was employed to recruit study subjects. In the designated central districts of Osaka City and Shizuoka (erroneously named as Shizoka in Lee's report $^{12}$ ) City, women interviewers from a market research company visited door to door to recruit 200 housewives (aged 20-55 years ) in each city. Each agreed to be interviewed and to provide a $50 \mathrm{ml}$ urine sample. A token gratuity (500 yen telephone card) was given in appreciation of their participation. The purpose of the project was explained as a general community health survey and ETS was not specifically mentioned. A second visit was made to collect urine samples, which were frozen and stored at a temperature of $-20^{\circ} \mathrm{C}$. The samples, contained in dry ice, were sent to the WinstonSalem Laboratory of RJ Reynolds for biochemical analysis. The results of the urine protein and urine sugar, but not the cotinine concentration results, were reported back to the participants by letter, accompanied with supplementary medical advice.

\section{Interview}

The interview was performed utilising a systematic questionnaire conducted in person. The smoking status of the subject, ETS exposure at home (smoking by husband, by other family member(s), or both) and that at the workplace, were ascertained by the response to the questions on the tobacco (cigarettes) use questionnaire. In particular, the length of wives' time spent in close stay with their husbands at home for both weekdays and holidays was sought. In addition, questions concerning food intake frequency (24 items with semi-quantitative food frequency questionnaires) and lifestyle (30 items), as well as self reported exposure to indoor air pollution from kitchen oven and heating, were also asked. At the end of the interview, details of active and passive smoking during the previous 48 hours were requested to double check the ETS exposure status. The interviews generally lasted from 20 minutes to one hour.

Measurement of cotinine: creatinine ratio (CCR) Urine samples were stored at $-20^{\circ} \mathrm{C}$ until assayed. Urinary cotinine was measured by enzyme linked immunosorbent assay (ELISA) method. ${ }^{29}$ Urinary creatinine was also measured, and urinary cotinine was expressed as nanograms per milligram of creatinine $(\mathrm{ng} / \mathrm{mg})(\mathrm{CCR})^{30}$ The laboratory cotinine analyses were performed blind to the smoking status of each subject but the overall purpose of the project was recognised.

\section{Second phase study (June 1992)}

The purpose of the second phase study was to check the reliability and validity of the first phase study, and also to evaluate any potential confounding bias caused by traffic air pollution. The same subjects who participated in the first phase study were approached and the same interviews repeated, without the urine sample collection. However, for the second phase study, the subjects were asked to self complete a standard questionnaire for respiratory symptoms and the distance of their house from major traffic was assessed using a map.

\section{Exposure monitoring study}

With reference to the results of the interview and CCR obtained in the first phase study (1991), 50 non-smoking subjects who were exposed to ETS from their husbands, and another 50 non-smokers with no exposure to ETS, were selected in Osaka for the exposure monitoring study. The subjects were requested to continually wear, except when bathing, a personal nicotine monitoring device for the full seven days. They were also asked to place another similar nicotine monitoring device in their living room. The uptake rate of the device was $31.5 \mathrm{ml} / \mathrm{min}$ and the limit of detection was between $0.01-0.02 \mu \mathrm{g}$. The concentration of cotinine was measured in both saliva and urine. Using a dental swab, the subjects were instructed to collect saliva samples at the beginning and end of the seven day survey period, and one additional sample on the third day. Urine samples were collected at the end of the seven days. For each of the seven days, the subjects were asked to complete a diary questionnaire about their exposure to ETS, both at home and at work. Special attention was paid to the collection of detailed and accurate information regarding the number of cigarettes smoked by their husbands when juxtaposed to the subjects.

\section{Measurement of nicotine and salivary cotinine}

Analysis for the nicotine attached to the filter of the device was performed by a gas chromatographic method after extraction. The collected saliva impregnated swabs were placed and sealed into plastic containers and frozen. After extraction of the saliva from the swab by centrifugation, cotinine was measured by radioimmunoassay. All the analysis was performed in Winston-Salem Laboratory of RJ Reynolds and the detailed method and the crude data ${ }^{31}$ were described in the tobacco industry document analysis by Hong and Bero.

\section{Data analyses}

Reliability was measured as the agreement between self reported smoking status in 1991 and 1992 using $\kappa$ statistics. The Spearman correlation coefficient between the urinary CCR, the average salivary cotinine value, and the nicotine concentration measured for one week using passive smoke monitors worn by the subjects, and also placed in the living room, were calculated to examine the validity of the CCR. To examine the relation of self reported ETS exposure with these laboratory indices, analysis of variance was performed. Also, differences in the diet and lifestyle of families with and without smoking husbands were examined by analysis of variance to evaluate confounding bias in the relation between ETS exposure and lung cancer.

\section{RESULTS}

\section{Characteristics of the subjects}

The total number of subjects used for the analyses were 196 from Osaka and 200 from Shizuoka. Subjects excluded from the Osaka dataset included one subject whose husband was away at work, and another three who did not provide complete information on smoking status. Comparison of the subject characteristics between the two cities is shown in Lee's report. ${ }^{12}$ For the following analysis, the subjects from the two cities were combined together. The average age of the subjects was 41 years old (range $22-55$ years). Seventy eight wives $(19.7 \%)$ self reported as current smokers, $32(8.1 \%)$ as

Table 1 Self reported current or previous smoking experience in 1991 and 1992

\begin{tabular}{|c|c|c|c|}
\hline 1992 & $\begin{array}{l}\text { Current } \\
\text { smoker }\end{array}$ & Ex-smoker & $\begin{array}{l}\text { Never- } \\
\text { smoker }\end{array}$ \\
\hline \multicolumn{4}{|l|}{1991} \\
\hline Current smoker & 69 & 5 & 3 \\
\hline Ex-smoker & 3 & 21 & 9 \\
\hline Never-smoker & 5 & 5 & 258 \\
\hline
\end{tabular}


ex-smokers, and $286(72.2 \%)$ as lifelong never-smokers. The average age of the never-smokers was significantly older than ever-smokers ( 42.8 years $v 36.7$ years; $p<0.001$ ), and the proportion of husbands' smoking was significantly lower for never-smoking wives than for ever-smoking wives $(51.0 \% \mathrm{v}$ $80.4 \%)$.

\section{Reliability of the self reported smoking status}

The reliability of the key information regarding smoking status and ETS exposure reported by the subjects in November 1991 and June 1992 is shown in tables 1 and 2. As the high $\kappa$ coefficients indicate, the repeated interview showed good agreement suggesting the high reliability of the response.

\section{Validity of the self reported smoking status in comparison with nicotine monitoring}

As can be seen in fig 1 , the correlation of both room and personal nicotine concentrations, and salivary cotinine concentrations, was significant, especially among the subjects with ETS exposure. However, the urinary CCR correlated neither with the nicotine concentration nor the salivary cotinine, in any of the groups.

Table 3 indicates that self reported ETS exposure correlated with both room nicotine concentration and personal nicotine exposure, while salivary cotinine did not. The average urinary CCR was slightly smaller in the subjects with ETS exposure than those without ETS exposure. Similar paradoxical relations between CCR and ETS exposure can be observed in the tables in Lee's report. ${ }^{12}$ For example, in lifelong nonsmoking wives, having a husband who currently smokes was related to a lower level of CCR compared with wives of nonsmoking husbands. If a wife had a smoking husband, heavy smoking at home did not necessarily increase her CCR (appendix table 1). For non-smoking wives, working and having any exposure to ETS was also related to lower median CCR (appendix table 2) (to view tables 1 and 2 in the appendix please visit the Tobacco Control website-http:// www.tobaccocontrol.com/supplemental).

\section{Possible misclassification of active smoking status}

Table 4 (table 2 in Lee's report ${ }^{12}$ ) shows the distribution of CCR by self reported smoking status. Lee claimed that 28 of $318(8.8 \%)$ self reported non-smokers were smokers misclassified by self report as non-smokers, which was much higher than the figures of between $1.9 \%$ and $3.4 \%$ obtained in the 10 country study by Riboli et al. ${ }^{32}$ However, Lee did not mention the 8 of $78(10.3 \%)$ self reported smokers misclassified by CCR as non-smokers, which was also very high compared to western studies. ${ }^{33}$ Such events can occur by random reporting error of smoking status or because of CCR measurement error.

\section{Confounding}

Comparing non-smoking women with and without ETS exposure, only one of 30 lifestyle items and two of 24 diet items revealed significant differences (appendix table 3 ) (to

Table 2 Self reported current smoking status or ETS exposure of non-smokers in 1991 and 1992

\begin{tabular}{|c|c|c|c|}
\hline 1992 & $\begin{array}{l}\text { Current } \\
\text { smoker }\end{array}$ & $\begin{array}{l}\text { Non-smoker } \\
\text { ETS (+) }\end{array}$ & $\begin{array}{l}\text { Non-smoker } \\
\text { ETS (-) }\end{array}$ \\
\hline \multicolumn{4}{|l|}{1991} \\
\hline Current smoker & 69 & 8 & 0 \\
\hline Non-smoker ETS (+) & 6 & 150 & 11 \\
\hline Non-smoker ETS (-) & 3 & 10 & 135 \\
\hline
\end{tabular}
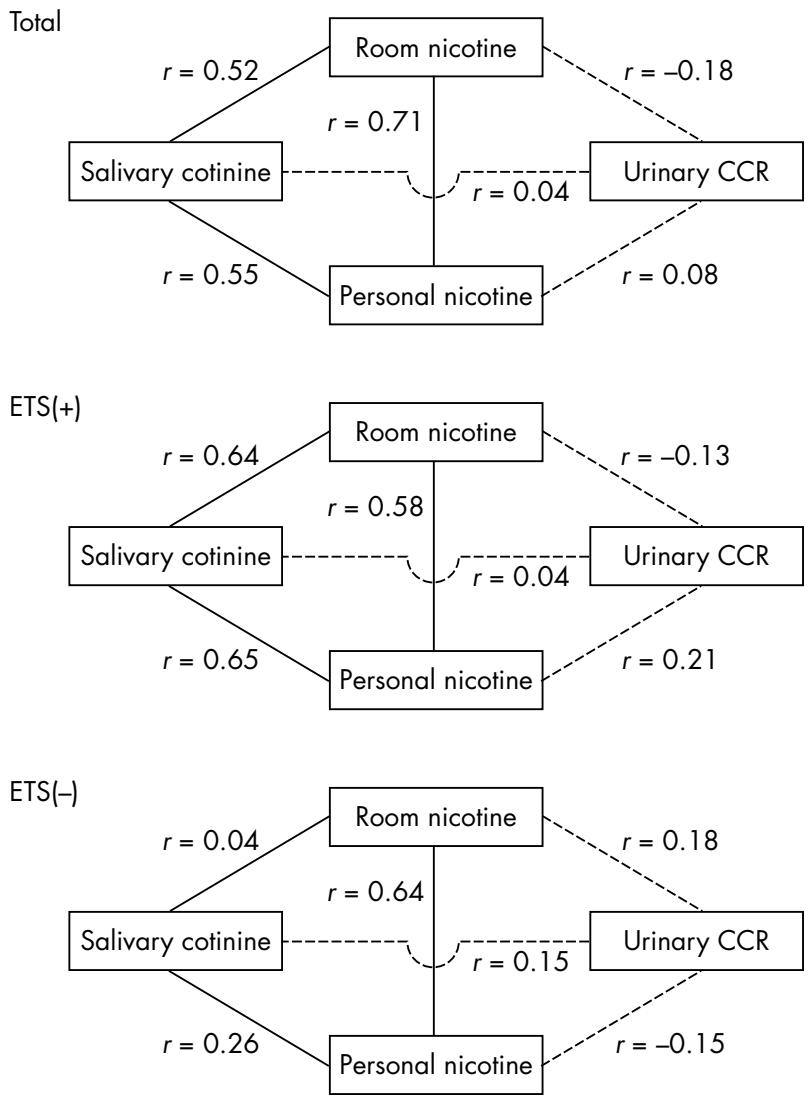

Figure 1 The Spearman correlation coefficient between the urinary cotinine: creatinine ratio (CCR), the average of salivary cotinine concentration, and the nicotine concentration measured for one week using passive monitors worn by the subjects, and also placed in the living room measured in Osaka in 1992. Data were shown for the total subjects and for those with (ETS+) and without (ETS-) environmental tobacco smoke exposure.

view table 3 in the appendix please visit the Tobacco Control website-http://www.tobaccocontrol.com/supplemental). After excluding women with CCR $>100 \mathrm{ng} / \mathrm{mg}$, "taking breakfast/lunch with husband" and frequency of juice drinking were significantly related to smoking status. However, considering the number of repetitions of the comparison, the significant relations could have arisen merely by chance.

\section{DISCUSSION}

The present study demonstrated a high reliability of self reported smoking status. Also, the measurement of nicotine concentration suggests high validity of self reported ETS exposure and invites a question about the validity of the CCR in this study. The CCR data were misrepresented in Lee's report.

Lee has claimed that a higher proportion of misclassified current smoking Japanese women were included in the nonsmoking group, when self reporting was used for the definition of smoking status and CCR was used as the gold standard. In general, cotinine is regarded as the objective index of smoking status, ${ }^{34}{ }^{35}$ and CCR in excess of $100 \mathrm{ng} / \mathrm{mg}$ (sometimes $50 \mathrm{ng} / \mathrm{mg}$ ) is used as a cut-off value to distinguish active from passive smokers. ${ }^{32}$ However, on close examination of the data from self reported smokers in table 4 (Lee's table 2), we see that a similar percentage of CCR determined non-smokers were misclassified as current smokers by self report, which was also in contrast to western 
Table 3 Self reported environmental tobacco smoke (ETS) exposure and the laboratory indices (mean (SD))

\begin{tabular}{|c|c|c|c|c|c|}
\hline & n & ETS(+) & n & ETS(-) & F value \\
\hline Urinary CCR $(\mathrm{ng} / \mathrm{mg}$ ) & 47 & $18.4(15.1)$ & 47 & $19.5(15.3)$ & 0.14 \\
\hline Salivary cotinine $(\mathrm{ng} / \mathrm{ml})$ & 50 & $2.25(4.1)$ & 44 & $1.54(3.54)$ & 0.80 \\
\hline Room nicotine $\left(\mu \mathrm{g} / \mathrm{m}^{3}\right)$ & 48 & $0.14(0.18)$ & 43 & $0.02(0.10)$ & $14.9^{* * *}$ \\
\hline Personal nicotine $\left(\mu \mathrm{g} / \mathrm{m}^{3}\right)$ & 47 & $0.18(0.38)$ & 44 & $0.02(0.10)$ & 6.96 ** \\
\hline
\end{tabular}

studies. Lee speculated that cultural attitudes and constraints against women smoking may be higher in Japan when compared to western countries. However, if this were the case it would be incomprehensible for non-smoking women to claim to be current smokers. This thus raises doubts concerning the value of the CCR as an objective and valid measure of smoking status.

Furthermore, there were also several inverse relations of ETS exposure or smoking status and CCR in almost half of tables 3 and 5 of Lee's report (reproduced as appendix table 1 and 2). Although the differences may be small and could be due to chance, this raises further doubt about the credibility of the CCR in this study.

In addition to the misrepresentation of the facts demonstrated in his own paper, Lee did not report some of the important findings obtained in the project, which was the validity of the self reported ETS exposure status confirmed by the two nicotine indices of personal exposure and ambient concentration, and very low correlation of CCR with the nicotine indices. Salivary cotinine correlated with the nicotine indices when ETS exposure was present, but there was a slight negative correlation between room concentration of nicotine and urinary CCR. Since current smokers were not included in the validation study, only the non-smoking women with and without ETS exposure can be compared, but this again showed low validity of CCR in this study.

Another fact not mentioned in Lee's report was the results of the confounding study, which was one of the two main purposes of the project. Despite the very elaborate questionnaire, no apparent difference in diet or lifestyle was observed when non-smoking wives with and without ETS exposure were compared. Hence, the original hypothesis that families with smoking husbands have different diets or lifestyles compared to those with non-smoking husbands was not supported. Therefore the association between ETS exposure and the higher incidence of lung cancer in the wives of smokers cannot be explained by confounding bias.
Together, these findings suggest that the CCRs used in this study were not necessarily valid. The misclassification could therefore possibly be due to the unreliable CCR rather than to self reporting smoking status. One study has indicated the exaggeration of ETS exposure by CCR due to smoking associated change of urine flow, ${ }^{36}$ whereas in general, urinary cotinine has been regarded a valid measure to detect ETS exposure. $^{37} 38$ Since the measurement of CCR was done without knowledge of the smoking status of each subject, there was no opportunity for measurement bias; however, for whatever reason the CCR measurement was not valid in detecting ETS, it could lead to mere random misclassification of smoking status for both smokers and non-smokers. If this occurred, the resulting random misclassification could be a source of bias. The data in table 4 (Lee's table 2) are compatible with this assumption. The data were not biased, although Lee's commentary on the data was biased.

Contrary to Lee's assertion, a valid interpretation of Lee's table 2 strengthens Hirayama's findings. Random misclassification generally inclines the effect measure (odds ratio) toward the null. ${ }^{39}$ If the same random misclassification affected the original Hirayama's spouse study, the results he obtained would be biased towards the null and the magnitude of the effect of ETS exposure in causing lung cancer may have been underestimated in his study. If the misclassification were to be corrected in Hirayama's study, the true odds ratio could be larger than he reported, showing an even stronger association between ETS exposure and lung cancer.

Since the original study was performed, there have been several studies and reviews ${ }^{40-44}$ which examined the misclassification of smoking status by self report, including a Japanese study. ${ }^{41}$ Most of these ${ }^{40-43}$ indicated that even if there is misclassification of smoking status through self report, it is small and unlikely to explain the increased health risks observed in epidemiological studies on ETS. Also the possible confounding by lifestyle differences between

Table 4 Cotinine: creatinine ratio (CCR) by self reported smoking status (equivalent to Lee's table 2)

\begin{tabular}{|c|c|c|c|c|c|c|c|}
\hline & $\begin{array}{l}\text { Non-smoker } \\
\text { n (\%) }\end{array}$ & Subtotal* & $\begin{array}{l}\text { Never-smoker } \\
\text { n (\%) }\end{array}$ & $\begin{array}{l}\text { Ex-smoker } \\
n(\%)\end{array}$ & $\begin{array}{l}\text { Current smoker } \\
\text { n (\%) }\end{array}$ & Subtotal ${ }^{*}$ & Total \\
\hline \multicolumn{8}{|l|}{ CCR (ng/mg) } \\
\hline 0 & $84(26.4)$ & & $78(27.3)$ & $6(18.8)$ & $1(1.3)$ & & \\
\hline $2-$ & $29(9.1)$ & & $23(8.0)$ & $6(18.8)$ & $1(1.3)$ & & \\
\hline $10-$ & $95(29.9)$ & & $86(30.1)$ & $9(28.1)$ & $2(2.6)$ & & \\
\hline $25-$ & $64(20.1)$ & & $61(21.3)$ & $3(9.4)$ & $1(1.3)$ & & \\
\hline $50-$ & $18(5.7)$ & 290 & $16(5.6)$ & $2(6.3)$ & $3(3.8)$ & 8 & 298 \\
\hline $100-$ & $3(0.9)$ & & $3(1.0)$ & $0(0.0)$ & $4(5.1)$ & & \\
\hline $250-$ & $2(0.6)$ & & $1(0.3)$ & $1(3.1)$ & $9(11.5)$ & & \\
\hline $500-$ & $6(1.9)$ & & $4(1.4)$ & $2(6.3)$ & $9(11.5)$ & & \\
\hline $1000-$ & $9(2.8)$ & & $8(2.8)$ & $1(3.1)$ & $18(23.1)$ & & \\
\hline 2000 & $8(2.5)$ & 28 & $6(2.1)$ & $2(6.3)$ & $30(38.5)$ & 70 & 98 \\
\hline Total & $318(100.0)$ & & $286(100.0)$ & $32(100.0)$ & $78(100.0)$ & & 396 \\
\hline Median CCR (ng/mg) & 17.4 & & 17.4 & 13.6 & 1482.8 & & \\
\hline Median cotinine $(\mathrm{ng} / \mathrm{ml})$ & 14.3 & & 14 & 16.5 & 1681.8 & & \\
\hline Median creatinine $(\mathrm{mg} / \mathrm{ml})$ & 0.91 & & 0.91 & 1.06 & 1.05 & & \\
\hline
\end{tabular}




\section{What this paper adds}

Association of exposure to environmental tobacco smoke (ETS) and lung cancer was first reported by a large cohort study in Japan. However, the study was challenged by Lee who claimed that in comparison to western countries, a higher proportion of current smoking Japanese women were misclassified as non-smokers as indicated by the urinary cotinine/creatinine ratio (CCR), thus creating an overestimation of the risk of ETS to cause lung cancer.

Some of the data on which lee based his report were at variance with his conclusions, and suggest the dubious validity of CCR as an index of smoking status. The data obtained, but not reported by Lee, showed high correlation of self reported exposure status to ETS with nicotine exposure and salivary cotinine concentrations, but not with the CCR. This finding has raised questions as to the value of the CCR as the gold standard in the verification of self reported smoking status, and therefore the credibility of Lee's conclusion.

non-smoking women, with and without a spouse who smoke, has been investigated by many researchers. Hackshaw quantitatively evaluated the effect of such possible confounding in eight other studies, concluding it to be negligible. ${ }^{45}$

In addition to the misrepresentation and misappropriation of results by a researcher with an extensive history of association with the tobacco industry, there have been attempts to intimidate and suppress scientific findings by anti-tobacco lobby campaigners in Japan. ${ }^{46} 47$ Induced by misleading translations ${ }^{47}$ of the article by Hong and Bero, ${ }^{6}$ they have rejected any informed discussion concerning the Hirayama study. I have been accused of questioning the validity of the Hirayama study, which they regarded as sacrosanct and not to be re-examined. ${ }^{46}{ }^{47}$ Demands have been made that my medical school should censor my research and publications in this regard..$^{49}$ My offers of an inquiry and an open forum to examine the matter have been refused $^{51}$ and condemn other's explanation as metaphysics without discussion. ${ }^{52}$ My personal and scientific concern for the unauthorised publication and misuse of data by Lee has prompted the revisiting of this issue. Likewise, I consider it imperative for the integrity of scientific research that any distortion of scientific findings, by either pro- or antismoking campaigners, is counteracted.

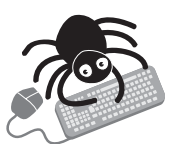

To view tables $1-3$ in the appendix please visit the Tobacco Control website-http://www. tobaccocontrol.com/supplemental

Competing interests: none declared

\section{REFERENCES}

1 Hirayama T. Non-smoking wives of heavy smokers have a higher risk of lung cancer: a study from Japan. BMJ 1981;282:183-5.

2 Mantel N. Epidemiologic investigation - care in conduct, care in analysis and care in reporting. J Cancer Res Clin Oncol 1983;105:113-6.

3 Yanagawa T. Hirayama story (in Japanese). In: Yanagawa T, ed. Risan Henryou no Kaiseki (Analysis of Discrete Data). Tokyo: Kyouritsu Shuppan, 1986:125-30.

4 Hirayama T. Cancer mortality in nonsmoking women with smoking husbands based on a large-scale cohort study in Japan. Prev Med 1984;13:680-90.

5 Garfinkel L. Time trends in lung cancer mortality among nonsmokers and a note on passive smoking. J Natl Cancer Inst 1981;66:1061-6.

6 Hong MK, Bero LA. How the tobacco industry responded to an influential study of the health effects of secondhand smoke. BMJ 2002;325:1413-6.

7 Covington \& Burling. Proposal for an applied research study to investigate exposure to environmental tobacco smoke in non-smoking Japanese women. August 1991. http://legacy.library.ucsf.edu/tid/jpn34e00.

8 Proctor CJ. Fax to E Yano, Teikyo University April $71992 \mathrm{http}: / /$ tobacco.health.usyd.edu.au/tds/CB_MIS_00004.
9 Untitled paper. Fax from Covington \& Burling to E Yano Received October 14 1992 http://tobacco.health.usyd.edu.au/tds/CB_MIS_00016.

10 Yano E. Handwritten note to Dr. C. Proctor, Covington \& Burling. October 27 1992. http://tobacco.health.usyd.edu.au/tds/CB_MIS_00008.

11 Proctor CJ. Fax to Dr E. Yano, Teikyo University re: A comparison of lifestyle factors for Japanese non smoking women married to smokers with those married to nonsmokers, October 30 1992. hitp://tobacco.health. usyd.edu.au/tds/CB_MIS_00006.

12 Lee PN. "Marriage to a smoker" may not be a valid marker of exposure in studies relating environmental tobacco smoke to risk of lung cancer in Japanese non-smoking women. Int Arch Occup Environ Health 1995;67:287-94.

13 Kagawa J, Yano E. Confounding factors in epidemiologic studies of spousal smoke exposure in Japanese women. April 21 1992. hitp:// legacy.library.ucsf.edu/tid/ttz53d00.

14 Yano E, Kagawa J, Lee PN. Confounding factors in epidemiologic studies of spousal smoke exposure in Japanese women. May 28 1992. hitp:// legacy.library.ucsf.edu/tid/bow63d00.

15 Yano E, Kagawa J, Lee PN. Lack of validity of marriage to a smoker as a marker of environmental tobacco exposure among Japanese non-smoking women. June 25 1992. http://bat.library.ucs.edu/data/l/r/g/lrg42a99/ women. June
lrg42a99.pdf.

16 Proctor CJ. Fax to E. Yano. April 14 1993. http://tobacco.health. usyd.edu.au/tds/CB_MIS_00002

17 Proctor CJ. Fax to E. Yano. April 21 1993. http://tobacco.health. usyd.edu.au/tds/CB_MIS_00001

18 Yano E. Letter to Dr. C.J. Proctor, Covington \& Burling re: Japanese spousal study, July 7 1993. http://tobacco.health.usyd.edu.au/tds/CB_MIS_00003.

19 Monthly activities HER, S\&T FTR/PM Neuchatel. June 24 1993. hitp:// legacy.library.ucsf.edu/tid/hoi56e00.

20 Proctor CJ. Letter: Japanese spousal study. July 26 1993. http:// legacy.library.ucsf.edu/tid/opn34e00.

21 Adlkofer F, Scherer G, Conze C, et al. Significance of exposure to benzene and other toxic compounds through environmental tobacco smoke. J Cancer Res Clin Oncol 1990;116:591-8.

22 Mueller L. Meeting of the working group on biological effects of sidestream smoke exposure. (letter) December 15 1993. http://legacy.library.ucsf.edu/ $\mathrm{tid} / \mathrm{bkv} 59 \mathrm{e} 00$.

23 Scherer G. Telefax an die Mitglieder der ad-hoc-Arbeitsgruppe 'Molekularbiologie': Prof. Adlkofer (VDC), Dr. Elmenhorst (Rothmans), Dr. Klus (Austria), Dr. Muller (RJR), Dr. Roper (Reemtsma), Dr. Tricker/Dr. Walk (PM), Dr. Wibert (BAT), Dr. Krause (Labor Munchen), Dr. Scherer. September 28 1995. http://legacy.library.ucsf.edu/tid/dmy22d00.

24 Colby FG. Telephone information obtained from Dr Oskar Stuhl on the January 18, 1983 (830118) meeting of the scientists (TFA) of the Verband. January 191983 http://legacy.library.ucsf.edu/tid/aup23a00.

25 Adlkofer F. Fax to Yano E. November 22 1994. http:// tobacco.health.usyd.edu.au/tds/CB_MIS_00017.

26 Yano E. Fax to Dr. F. Adllkofer. November $1994 \mathrm{http}: / /$ tobacco.health.usyd.edu.au/tds/CB_MIS_00014.

27 Lee PN. Limitations of studies of lung cancer and environmental tobacco smoke exposure in Japanese non-smoking women. Philip Morris. 18 May 1994. http://legacy.library.ucsf.edu/tid/qil42e00.

28 Lee PN. Letter to G Lehnert. April 11 1995. http:// tobacco.health.usyd.edu.au/tds/details.jsp?document_id = BAT50083371 1 / 3712 \&number $=1$.

29 Bjercke RJ, Cook G, Rychlik N, et al. Stereospecific monoclonal antibodies to nicotine and cotinine and their use in enzyme-linked immunosorbent assays. $\mathrm{J}$ Immunol Methods 1986;90:203-13.

30 Thompson SG, Barlow RD, Wald NJ, et al. How should urinary cotinine concentrations be ajusted for urinary creatinine concentration? Clinica Chimica Acta 1990;187:289-96.

31 Ogden MW. RJ Reynolds Senior Staff R\&D Chemist "letter to Dr. C Proctor" on November 4, 1992. http://legacy.library.ucsf.edu/tid/gtz53d00.

32 Riboli E, Preston-Martin S, Saracci R, et al. Exposure of nonsmoking women to environmental tobacco smoke: a 10 -country collaborative study. Cancer Causes Control 1990;1:243-52.

33 Pirkle JL, Flegal KM, Bernert JT, et al. Exposure of the US population to environmental tobacco smoke: the Third National Health and Nutrition Examination Survey, 1988 to 1991. JAMA 1996;275:1233-40.

34 Benowitz NL. Biomarkers of environmental tobacco smoke exposure. Environ Health Perspect 1999;107(suppl 2):349-55.

35 International Agency for Research on Cancer. Tobacco smoke and involuntary smoking. IARC Monographs on the Evaluation of Carcinogenic Risks to Humans. Vol. 83. Lyon: IARC, (France).

36 Kihara $M$, Kihara $M$, Okamoto $N$, et al. Limited value of urinary cotinine creatinine ratio as an indicator for tobacco smoke exposure. J Epidemiol 1992;2:91-5.

37 Matsukura S, Taminato T, Kitano N, et al. Effects of environmental tobacco smoke on urinary cotinine excretion in nonsmokers. Evidence for passive smoking. N Engl J Med 1984;311:828-32.

38 Benowitz NL. Cotinine as a biomarker of environmental tobacco smoke exposure. Epidemiol Rev 1996;18:188-204.

39 Rothman JK, Greenland S. Precision and validity in epidemiologic studies. In: Rothman JK, Greenland S, eds. Modern epidemiology, 2nd ed. Philadelphia: Lippincott-Raven Publishers, 1998:115-34.

40 Riboli E, Haley NJ, Tredaniel J, et al. Misclassification of smoking status among women in relation to exposure to environmental tobacco smoke. Eur Respir J 1995;8:285-90. 
41 Ozasa K, Higashi A, Yamasaki M, et al. Validity of self-reported passive smoking evaluated by comparison with smokers in the same household. J Epidemiol 1997;7:205-9.

42 Wells AJ, English PB, Posner SF, et al. Misclassification rates for current smokers misclassified as nonsmokers. Am J Public Health 1998;88:1503-9.

$43 \mathrm{Wu} \mathrm{AH}$. Exposure misclassification bias in studies of environmental tobacco smoke and lung cancer. Environ Health Perspect 1999;107(suppl 6):873-7

44 Lee PN, Fry JS, Forey B. Revisiting the association between environmental tobacco smoke exposure and lung cancer risk V. Overall Conclusion. IndoorBuilt Environ 2002;11:59-82.

45 Hackshaw AK. Lung cancer and passive smoking. Stat Methods Med Res 1998;7:119-36.

46 Sono IH (Kobe, Hyogo). An open inquiry was sent to Mr. Eiji Yano, Teikyo University (in Japanese) http://www.egroups.co.jp/message/ tokyopublichealth/8574 (accessed 13 July 2003, retrievable as supplement file 2 with a machine translation into English).

47 Watanabe B. Tabako Mondai Joho Senta (Information Centre for Tobacco Problems) 13 Feb, 2003. Tokyo. (in Japanese) http://home.att.ne.jp/star/ publichealth/bungaku.htm (accessed 13 July 2003, retrievable as supplement file 3 with a machine translation into English).
48 Kiriake Y. A project to conceal hazardous effects of passive smoking. Tokyo Local Court 1998 (wa) No 10379 Damage Compensation Claim for Tobacco Diseases. Evidence (Kou) No. 112. February 14, 2003 (Also available at http://www.geocities.co.jp/Beautycare-Venus/6700/sojyou/kou38.pdf).

49 Kakezono H (Kashima, Saga). An open inquiry to president of Teikyo University: On the rotten practice of Yano, Professor in Medical School (in Japanese). March 17, 2003. To be retrievable as supplement file 5 with a machine translation into English).

50 Yamaoka M (Sumoto, Hyogo). A confidential letter to President of Teikyo University: An inquiry to the research of a faculty in your school (in Japanese). April 21, 2003. (To be retrievable as supplement file 6 with a machine translation into English).

51 Watanabe B. A paper to conceal the harm of passive smoking: Did Professor Yano, Teikyo University make commitment? Kin-en Journal (Journal for Smoking Cessation) No 148. 1 March 2003. Tabako Mondai Joho Senta (Information Centre for Tobacco Problems) Tokyo. (in Japanese; retrievable as supplement file 4 with a machine translation into English).

52 Tsuda T. Igakusha ha Kogaiijken de Nani wo Shitekitanoka (How have the Medical Academes acted toward Environmental Problems?). Tokyo: Iwanamishoten, 2004

\section{COMMENTARY}

\section{Japanese spousal study: a response to Professor Yano's claims}

\section{P N Lee}

a agree with Yano that scientific integrity should be maintained and researchers be free from pressure from commercial and campaigning interests. I disagree that I have caused any "distortion of scientific findings" or "misrepresentation and misappropriation" of results, serious charges which I will show are unjustified. To clarify the situation I will start with the history preceding the study.

In 1981 Hirayama reported an increased lung cancer risk in non-smoking women married to smokers. ${ }^{1}$ Following this I demonstrated random misclassification of smokers as nonsmokers, coupled with smokers tending to marry smokers, leads to an observed increased risk even when environmental tobacco smoke (ETS) has no effect. ${ }^{2}{ }^{3}$ The tobacco industry then agreed to support a study in England of this "misclassification bias", using cotinine to validate smoking, which was reported in 1987. ${ }^{4}$ I also reviewed evidence on misclassification, ${ }^{5}$ revealing the lack of useful data in Japan, where cultural differences might affect reporting of smoking.

Several tobacco companies therefore decided to fund a study there. The protocol, drafted by Proctor and discussed with me, included two major phases. Phase I, described in my paper, ${ }^{6}$ mainly concerned misclassification, using urinary cotinine/creatinine ratio (CCR) to validate smoking, but also collected data on dietary/lifestyle factors. Phase II mainly involved comparing different ETS markers. The study was organised in Japan by Yano, who discussed the design and findings with Proctor.

Proctor sent me the phase I data in 1992, but I have never seen the phase II data. I conducted statistical analyses and helped draft possible papers for publication. The exact history is now unclear to me, but discussions occurred between myself and Proctor, and Proctor and Yano, as to how best to present the findings. I felt then that Yano did not fully understand the complexities of misclassification. Eventually, after discussions with Yano, Proctor asked me to author a paper including suitable acknowledgements to Yano and for the funding.
Below I comment on Yano's criticisms of my analyses. ${ }^{6}$

\section{RELIABILITY OF CCR}

I mainly used CCR to detect misclassified smokers. As Yano's table 4 shows, current smokers had a median CCR almost 100 times that of non-smokers, with values $>100 \mathrm{ng} / \mathrm{mg}$ seen in $90 \%$ of smokers and only $9 \%$ of non-smokers. This counters Yano's claim that CCR was an invalid marker of self reported smoking. Nicotine based markers are commonly used to detect misclassified smokers. ${ }^{78}$

I found little relationship of CCR in non-smokers to husband's smoking, consistent with other evidence ${ }^{8}$ that CCR is a valid marker of smoking, but less good as a marker of ETS exposure. Yano appears to argue that CCR is invalid generally. My main conclusion, of high misclassification rates in Japanese women, depends only on CCR being a valid marker of active smoking.

\section{SMOKERS WITH LOW CCR VALUES}

Some current smokers have low values, possibly because they have not smoked recently, though the reasons for this are not fully understood. ${ }^{8}$ The percentage of self reported smokers among women with CCR $<100 \mathrm{ng} / \mathrm{mg}(8 / 298=2.7 \%)$ was much less than the percentage of self reported non-smokers among women with CCR > $100 \mathrm{ng} / \mathrm{mg}(28 / 98=28.6 \%)$. Also the bias to the lung cancer/spousal smoking relationship that results from smokers denying smoking much exceeds the corresponding bias resulting from non-smokers claiming to smoke. ${ }^{9}$ I therefore concentrated on the former misclassification.

Yano claims that misclassification of self reported smokers as non-smokers $(8 / 78=10.3 \%)$ and of non-smokers as smokers $(28 / 318=8.8 \%)$ are similar. This erroneously uses self report, not CCR, as the "gold standard". One uses CCR to detect true smokers and hence calculate misclassification rates. 


\section{COMPARISON WITH WESTERN POPULATIONS}

Not only this study, but also two other biomarker studies of Asian women, show misclassification rates substantially higher than seen in western populations. ${ }^{10}$

\section{EFFECTS OF RANDOM MISCLASSIFICATION}

Yano argues that random misclassification underestimates true associations. This is so for smoking by the spouse (used as the exposure variable) but not for smoking by the woman (used as the variable to select the non-smokers for analysis). ${ }^{2}{ }^{3}$ The biasing effect of a given level of misclassification to the lung cancer/spousal smoking relationship is much less for spousal than for subject smoking. ${ }^{9}$

\section{CONFOUNDING BY LIFESTYLE FACTORS}

Meta-analyses show that, in non-smokers, lung cancer risk and ETS exposure are both associated with a poorer diet (less fruit and vegetables, more dietary fat) and poorer education, and that the resulting confounding effect is non-negligible. ${ }^{11}$ Earlier versions of my paper included a table showing that marriage to a smoker was generally associated with a poorer lifestyle, but not significantly, due probably to the small sample. After one journal rejected the paper I simplified it, concentrating on misclassification issues. However, my discussion section ${ }^{6}$ still cites some confounding results, overlooked by Yano.

\section{KAPPA COEFFICIENTS}

Yano believes high kappas for repeat interview data indicate a reliable response. I would regard some subjects claiming in 1992 never to have smoked and in 1991 to have smoked as indicating some unreliability. Also, some subjects may have consistently denied smoking. There is much literature that demonstrates the inconsistency of reported smoking. ${ }^{7}$

I never intended to present all the available findings fully, concentrating on smoking misclassification in Japanese women. The phase II ETS data were only for non-smokers and would not have contributed to this. Yano has not demonstrated any distortion or misrepresentation, or that I "reached conclusions...totally at odds with the actual findings." I stand by my conclusions.

Competing interests: Peter Lee is a long term consultant to the tobacco industry.

Correspondence to: Mr Peter Lee, P N Lee Statistics and Computing Ltd, 17 Cedar Road, Sutton, Surrey SM2 5DA, UK; PeterLee@pnlee.demon. co.uk

\section{REFERENCES}

1 Hirayama T. Non-smoking wives of heavy smokers have a higher risk of lung cancer: a study from Japan. BMJ 1981;282:183-5.

2 Lee PN. Passive smoking. Can observed associations with health be artefacts of measurement error? Sutton, Surrey: P N Lee Statistics and Computing Ltd, 1983. www. pnlee.co.uk

3 Lehnert G. Roundtable discussion. Prev Med 1984;13:730-46.

4 Lee PN. Lung cancer and passive smoking: association an artefact due to misclassification of smoking habits? Toxicol Lett 1987;35:157-62.

5 Lee PN. Misclassification of smoking habits and passive smoking. A review of the evidence. Int Arch Occup Environ Health 1988;(suppl): 103. Heidelberg: Springer-Verlag.

6 Lee PN. "Marriage to a smoker" may not be a valid marker of exposure in studies relating environmental tobacco smoke to risk of lung cancer in Japanese non-smoking women. Int Arch Occup Environ Health 1995;67:287-94

7 Lee PN, Forey BA. Misclassification of smoking habits as determined by cotinine or by repeated self-report - a summary of evidence from 42 studies. J Smoking Related Dis 1995:6:109-29.

8 Lee PN. Uses and abuses of cotinine as a marker of tobacco smoke exposure. In: Gorrod JW, Jacob P, III, eds. Analytical determination of nicotine and related compounds and their metabolites. Amsterdam: Elsevier, 1999:669-719.

9 Lee PN, Forey BA. Misclassification of smoking habits as a source of bias in the study of environmental tobacco smoke and lung cancer. Stat Med 1996;15:581-605.

10 Lee PN. Passive smoking and lung cancer: Strength of evidence on passive smoking and lung cancer is overstated [letter]. BMJ 1998;317:346-7

11 Fry JS, Lee PN. Revisiting the association between environmental tobacco smoke exposure and lung cancer risk. II. Adjustment for the potential confounding effects of fruit, vegetables, dietary fat and education. Indoor Built Environ 2001;10:20-39.

\section{Response to PN Lee}

\section{E Yano}

$\mathrm{P}$ eter Lee wants to maintain scientific integrity in research, but his understanding of "integrity" seems very different to mine. I was a named principal investigator on the study. Professor Adlkofer advised him that "no-one was better informed of the progress of the study...than Dr Yano...Professor Wynder and I....would find it advisable if Dr Yano published the results as lead author". ${ }^{1}$ Despite this, he used my data in his paper without my consent, crediting me only with "assistance provided in Japan". ${ }^{2}$ Now, beyond acknowledging that I organised the study and collected the data, and asserting that the charge of misappropriation is unjustified without offering an explanation, he makes no comment on his failure to contact me. Let the record stand then, that he used my data without my consent, and when given an opportunity to comment on this, failed to acknowledge this or apologise.

The conclusions of Lee's review of misclassification bias ${ }^{3}$ were not supported by this study where there were more self

reported smokers with low $(<100 \mathrm{ng} / \mathrm{mg})$ cotinine/creatinine ratio (CCR) compared to self reported non-smokers with high CCR. Proctor apparently momentarily agreed ("I certainly agree that in its original form it overstated some points"), with the draft of 31 October 1992 withdrawing the conclusion of higher misclassification of female smokers as non-smokers in Japan. ${ }^{4}$

Lee writes that I claim that the "misclassification of selfreported smokers as non-smokers $(8 / 78=10.3 \%)$ and of non-smokers as smokers $(28 / 318=8.8 \%)$ are similar" arguing that "this erroneously uses self report, not CCR, as the 'gold standard'. One uses CCR to detect true smokers and hence calculate misclassification rates".

Here Lee seems confused with the calculation formula. His definition of misclassification was obtained by dividing those with $>100 \mathrm{ng} / \mathrm{mg}$ CCR $(\mathrm{n}=28)$ by self reported nonsmokers $(\mathrm{n}=318)$. He should certainly apply the same rule to the other side by dividing those with $<100 \mathrm{ng} / \mathrm{mg}$ CCR 
$(\mathrm{n}=8)$ by self reported smokers $(\mathrm{n}=78)$. If Lee claims that CCR is the gold standard, then why did he not use it to also detect true non-smokers? He keeps looking away from the fact that the misclassification rate for self reported smokers in this study is higher than the other western study. ${ }^{5}$ I do not know the reason for this. However, Lee's conclusion of high false non-smokers can be obtained simply by just measuring CCR poorly.

Here, I am compelled to point out that although the smoking status of each sample was not disclosed to those in the tobacco industry who analysed the sample, they knew the purpose of the project. Poor measurement of CCR caused by sample deterioration during transit to the USA or for other reasons could result in both high false non-smokers and false smokers.

Lee defends the "reliability" of his use of CCR to detect misclassified smokers. As he should know, reliability is a measure of the consistency of results after repeated measurements using a test or instrument. What Lee calls "reliability" in his reply refers to validity. Tests of validity examine how closely the results of a measurement correspond to the true state of the phenomenon being measured. Lee's statement that "with values > $100 \mathrm{ng} / \mathrm{mg}$ seen in $90 \%$ of smokers and only $9 \%$ of non-smokers" indicates that the validity of self reported smoking status in the study was about $90 \%$ when $>100 \mathrm{ng} / \mathrm{mg}$ of CCR is used as gold standard of smokingnothing more, nothing less. It was similarly valid in detecting falsely claimed non-smokers as well as falsely claimed smokers. By confusing basic terminology, Lee fails to understand that he cannot use the CCR, his gold standard for smoking, in examining the validity (his reliability) of self reported smoking status. Moreover, when he challenged the self reports of non-smokers, he used CCR, but he did not use it to verify self reported smokers.
Lee claims I overlooked his statement on confounding factors in his report which may have associated environmental tobacco smoke exposure with poor health outcomes by pathways other than causal ones. However, Lee cited confounding results only when the tendency of the (nonsignificant) data favoured his hypothesis. He did not, for example, consider that households with no smokers consumed less juice and more smoked fish than those with smokers.

Finally, I am astonished to learn that while Lee was involved in discussions with Proctor about the study protocol which included both a phase I and II, that he obtained only the results of phase I and, on his account, has never seen the phase II data.

Correspondence to: Professor Eiji Yano, Department of Hygiene and Public Health, Teikyo University School of Medicine, 2-11-1, Kaga, Itabashi-ku, Tokyo 173-8605, Japan; eyano@med.teikyo-u.ac.jp

\section{REFERENCES}

1 Adlkofer F. Fax to Yano E. November 22 1994. http:// tobacco.health.usyd.edu.au/tds/CB_MIS_00017.

2 Lee PN. "Marriage to a smoker" may not be a valid marker of exposure in studies relating environmental tobacco smoke to risk of lung cancer in Japanese non-smoking women. Int Arch Occup Environ Health 1996:67:287-94.

3 Lee PN. Misclassification of smoking habits and passive smoking. A review of the evidence. Int Arch Occup Environ Health 1988;(suppl):103. Heidelberg: Springer-Verlag.

4 Proctor CJ. Fax to Dr E. Yano, Teikyo University re: A comparison of lifestyle factors for Japanese non smoking women married to smokers with those married to nonsmokers. October 30 1992. http:// tobacco.health.usyd.edu.au/tds/CB MIS 00006.

5 Pirkle JL, Flegal KM, Bernert JT, et al. Exposure of the US population to environmental tobacco smoke: the Third National Health and Nutrition Examination Survey, 1988 to 1991. JAMA 1996;275:1233-40.

\section{Call for papers}

11 th European Forum on Quality Improvement in Health Care 26-28 April 2006, Prague, Czech Republic Deadline 30 September 2005.

For further information and to submit online go to: www.quality.bmipg.com 